\title{
COOPERAÇÃO E INOVAÇÃO PARA CRIAÇÃO DE INFRAESTRUTURA TECNOLÓGICA: A PARTICIPAÇÃO DAS EMPRESAS DO POLO AUTOMOTIVO SUL FLUMINENSE NO PROGRAMA INOVAR-AUTO
}

Erik Telles Pascoal ${ }^{1}$, Maurício César Delamaro ${ }^{2}$, Henrique Martins Rocha $^{3}$ e Valter Silva Ferreira Filho ${ }^{4}$

${ }^{1,2}$ UNESP-FEG

${ }^{3}$ UERJ

${ }^{4}$ UFRRJ

E-mails: erik.telles@ feg.unesp.br, delamaro@feg.unesp.br,

prof.henrique_rocha@yahoo.com.br, valterfilho8@yahoo.com.br

\section{RESUMO}

O novo regime automotivo brasileiro objetiva dar início a um novo patamar na evolução da infraestrutura tecnológica no país. Com o programa Inovar-Auto se pretende elevar o nível tecnológico associado aos produtos e processos da indústria automotiva nacional por meio de incentivos à $\mathrm{P} \& \mathrm{D}$, visando o desenvolvimento e produção de veículos mais modernos, seguros e eficientes.

Entretanto, se o programa define as diretrizes para melhorar a competitividade da indústria automotiva, caberão às empresas buscarem novas formas de cooperação com seus fornecedores, parceiros e instituições de ciência e tecnologia para atingirem os objetivos do programa.

Neste contexto, foi realizada uma pesquisa com executivos dos principais fornecedores de autopeças instalados no polo automotivo da região sul fluminense com o objetivo de evidenciar um panorama atual das atividades de $\mathrm{P} \& \mathrm{D}$ executadas nestas empresas, a partir dos requisitos do Inovar-Auto.

$O$ resultado da pesquisa demonstra que a maior parte das atividades de $\mathrm{P} \& \mathrm{D}$ realizadas nestes fornecedores não possui nenhuma parceria com as montadoras e, que as regras do InovarAuto não foram devidamente explicadas. Desta forma, recomenda-se que futuras políticas industriais busquem alternativas para uma melhor disseminação de suas diretrizes aos seus beneficiários.

\section{INTRODUÇÃO}

A indústria automotiva brasileira continua sendo um dos setores mais importantes para a economia nacional e internacional. Ela representa hoje quase $25 \%$ do PIB industrial e $5 \%$ do PIB total, com faturamento acima de US $\$ 100$ bilhões no ano de 2013 [1]. No cenário internacional o Brasil é o quarto maior mercado global de veículos com vendas anuais de 3,6 milhões e é o sétimo fabricante mundial, com 3,4 milhões de unidades produzidas [2], [3]. 
Os investimentos previstos por essa indústria até o ano de 2017 são da ordem de $\mathrm{R} \$ 76$ bilhões, destinados à ampliação, modernização e construção de novas fábricas e desenvolvimento de novos produtos [1], [4]. Na Figura 1 estão listadas as novas fábricas de automóveis em instalação no Brasil e os seus respectivos volumes anuais de produção previstos.

Figura 1: Novas Fábricas Automotivas em Instalação e seus Volumes Anuais de Produção.

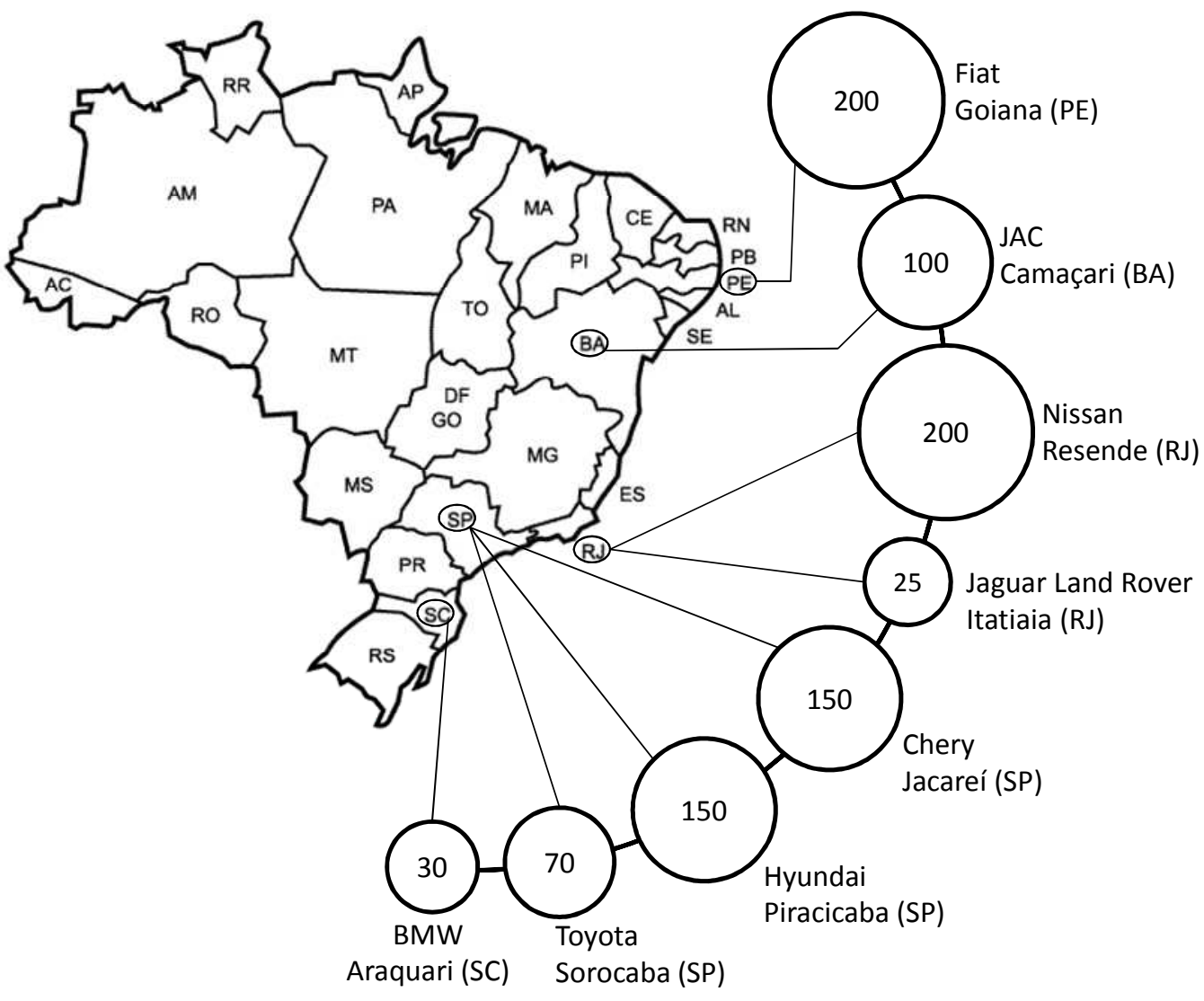

Fonte: Adaptado de Roland Berger, 2012 [5].

As projeções, no que se refere ao comportamento do mercado, são animadoras e revelam potencial de crescimento nos próximos anos, com a indústria automotiva brasileira podendo vir a produzir quase seis milhões de veículos/ano em 2020, desde que mantidas as perspectivas de estabilidade e de expansão da economia brasileira, além de adequadas condições de crédito e de acesso do consumidor ao mercado [6]. A Figura 2 apresenta a projeção de produção de veículos a partir de 2014 até 2020. 
Figura 2: Projeções de Produção de Veículos Leves no Brasil - 2014 a 2020.

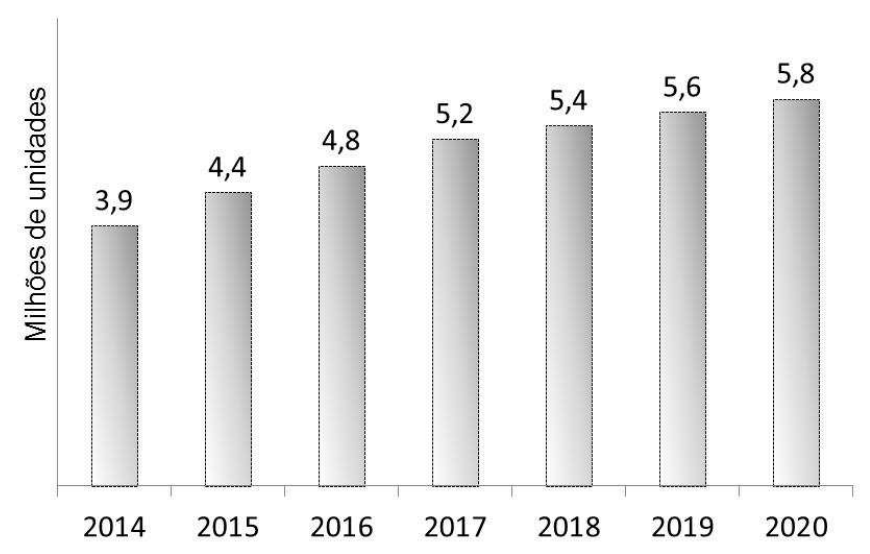

Fonte: Adaptado de KPMG, 2013 [6].

Em consonância a este cenário, o Governo Federal aprovou em Outubro de 2012 o novo regime automotivo brasileiro denominado Inovar-Auto, cuja vigência será de 2013 até 2017 [7], [8]. O programa busca incentivar as montadoras e seus fornecedores para produzir veículos mais eficientes, seguros e com maior tecnologia embarcada [7], [8], [9], [10], [11].

Um importante ponto do Inovar-Auto é que o governo atribui para o setor industrial uma função decisiva de promoção do desenvolvimento do país [9]. A principal diferença entre o Inovar-Auto e os outros regimes automotivos estabelecidos no Brasil desde a década de 50 é que, pela primeira vez, inovação é posicionada como um dos objetivos principais no contexto de uma política industrial [9].

É visível a representatividade do setor automotivo na economia do País, bem como a necessidade de aumento dos investimentos em tecnologia pelo setor e o Inovar-Auto ratifica o compromisso governamental com o aumento dos investimentos privados em inovação e desenvolvimento tecnológico [11].

Se há projeções de mercado e ações concretas da indústria com programas de investimentos, existem também sérios desafios à frente. Inicia-se um novo ciclo para a indústria automobilística no País, com o regime automotivo para o período 2013-2017 exigindo renovado compromisso de toda a cadeia automotiva quanto ao atendimento de metas de nacionalização e de investimentos em engenharia e inovação [12].

Com o Inovar-Auto um novo paradigma da relação montadora-fornecedor começa a se alterar de um ambiente de atrito para um cenário de colaboração onde a busca de melhorias se dá através da parceria e de mútuo aprendizado [13]. O Inovar-Auto através do requisito de capacitação de fornecedores cria mecanismos de incentivo às alianças estratégias entre as montadoras e seus fornecedores [14].

Neste contexto, tendo como referência os requisitos específicos do Inovar-Auto, foi realizada uma pesquisa com os principais fornecedores de autopeças do polo automotivo do sul fluminense com o objetivo de identificar a existência de parcerias com montadoras em atividades de P\&D. Este tipo de colaboração é essencial para o cumprimento de um dos 
objetivos esperados desta política industrial que é o fortalecimento da cadeia automotiva brasileira de modo a alavancar novos investimentos em engenharia, tecnologia e inovação; contribuindo, desta forma, para o aumento da competitividade do setor.

\section{O PROGRAMA INOVAR-AUTO}

O Programa de Incentivo à Inovação Tecnológica e Adensamento da Cadeia Produtiva de Veículos Automotores, denominado Inovar-Auto foi regulamentado pelo Governo Federal no dia 03 de outubro de 2012 através do Decreto $n^{\circ}$ 7.819/2012 e entrou em vigor em Janeiro de 2013 com validade até 2017 [7], [8].

O programa engloba montadoras que produzem no Brasil e também aquelas que só comercializam veículos no País, bem como àquelas que tenham projeto de investimento aprovado para instalação de fábrica no Brasil, abrangendo automóveis e comerciais leves, caminhões, chassis com motor e autopeças. O Inovar-Auto tem como principais objetivos apoiar o desenvolvimento tecnológico, a inovação, a segurança, a proteção ao meio ambiente, a eficiência energética e a qualidade dos veículos e autopeças [7], [8], [9], [10], [11].

Como benefício, o Inovar-Auto prevê a concessão de crédito presumido de imposto sobre produtos industrializados (IPI) sobre as aquisições de insumos estratégicos e ferramentaria, gastos com pesquisa, desenvolvimento tecnológico, inovação tecnológica, recolhimentos ao FNDCT (Fundo Nacional de Desenvolvimento Científico e Tecnológico) e dispêndios com engenharia e tecnologia industrial básica e capacitação de fornecedores [7], [8], [11].

As montadoras de veículos e comerciais leves para se habilitarem ao programa, deverão atender duas condições gerais: a) estar em dia em relação aos tributos federais; e b) assumir o compromisso de atingir os níveis mínimos de eficiência energética para os veículos comercializados no país [7], [8].

Além disto, para conseguirem os benefícios do programa, precisam realizar processos de manufatura no Brasil e escolher dois entre os três requisitos previstos: (1) investimentos em P\&D, (2) investimentos em engenharia, tecnologia industrial básica e capacitação de fornecedores, e (3) aderir ao Programa de Etiquetagem Veicular [7], [8], [15], [16]. Os dois primeiros requisitos específicos do Inovar-Auto, objeto deste artigo, são abordados a seguir.

O programa define os percentuais mínimos dos investimentos em $\mathrm{P} \& \mathrm{D}$, engenharia, tecnologia industrial básica e capacitação de fornecedores incidentes sobre a receita bruta das montadoras durante a vigência do Inovar-Auto, conforme descrito na Figura 3. 
Figura 3: Percentuais Mínimos dos Dispêndios em P\&D, Engenharia, Tecnologia Industrial Básica e Capacitação de Fornecedores.

\begin{tabular}{|c|c|c|}
\hline Ano & $\begin{array}{c}\text { Percentuais mínimos } \\
\text { de investimentos em } \\
\text { pesquisa e } \\
\text { desenvolvimento }\end{array}$ & $\begin{array}{c}\text { Percentuais mínimos } \\
\text { de investimentos em } \\
\text { engenharia, tecnologia } \\
\text { industrial básica e } \\
\text { capacitação de } \\
\text { fornecedores }\end{array}$ \\
\hline $\mathbf{2 0 1 3}$ & $0,15 \%$ & $0,50 \%$ \\
\hline $\mathbf{2 0 1 4}$ & $0,30 \%$ & $0,75 \%$ \\
\hline $\mathbf{2 0 1 5}$ & $0,50 \%$ & $1,00 \%$ \\
\hline $\mathbf{2 0 1 6}$ & $0,50 \%$ & $1,00 \%$ \\
\hline $\mathbf{2 0 1 7}$ & $0,50 \%$ & $1,00 \%$ \\
\hline
\end{tabular}

Fonte: Adaptado de MDIC, 2012 [7].

O Inovar-Auto considera como atividade de $\mathrm{P} \& \mathrm{D}$ a pesquisa básica dirigida, a pesquisa aplicada, o desenvolvimento experimental e o serviço de apoio técnico. Também poderá ser considerado o desenvolvimento de novos dispositivos de segurança veicular ativa e passiva, desde que sejam incorporados aos produtos até 30/07/2017 e constituam-se avanços funcionais e tecnológicos em relação aos previstos pelo Conselho Nacional de Trânsito (CONTRAN) [7], [8].

Para o outro requisito, as atividades consideradas são: desenvolvimento de engenharia; tecnologia industrial básica; treinamento do pessoal dedicado à pesquisa; desenvolvimento do produto e do processo; inovação e implementação; desenvolvimento de produtos, inclusive veículos, sistemas e componentes, autopeças, máquinas e equipamentos; construção de laboratórios para o desenvolvimento de engenharia e tecnologia industrial básica; desenvolvimento de ferramental e capacitação de fornecedores [7], [8].

É importante destacar que estes dois requisitos não são atividades realizadas exclusivamente pelas montadoras. $O$ próprio programa define que os dispêndios em pesquisa, desenvolvimento tecnológico, engenharia, tecnologia industrial básica e capacitação de fornecedores deverão ser realizados, no País: a) diretamente pelas montadoras; b) por intermédio de fornecedor contratado; ou c) por intermédio de contratação de universidade ou instituição de pesquisa [7], [8].

\section{SOBRE AS ATIVIDADES DE P\&D E ENGENHARIA}

$\mathrm{O}$ incentivo do Inovar-Auto no investimento em atividade de $\mathrm{P} \& \mathrm{D}$ e engenharia é uma medida que demonstra o compromisso das políticas públicas de aumento dos investimentos privados em inovação [11].

Entretanto, alguns autores ressaltam que as exigências de investimentos definidas pelo programa são inferiores aos valores já realizados pela grande maioria das montadoras no país [11], [17]. O setor de fabricação de veículos automotores investiu em atividades de P\&D no 
período de 2009 a 2011 o montante de $\mathrm{R} \$ 3.3$ bilhões o que representa 1,28\% de sua receita líquida [18].

Já no setor de autopeças, recente pesquisa realizada pelo Sindicato Nacional da Indústria de Componentes para Veículos Automotores (SINDIPEÇAS), apontou que do total do faturamento do setor em 2013 , o equivalente a $\mathrm{R} \$ 86$ bilhões, entre $0,50 \%$ e $0,75 \%$ da receita das autopeças, foi aplicado em P\&D [19].

Os investimentos em P\&D talvez sejam a forma mais correta para que as empresas nacionais possam se tornar eficientes e competitivas para enfrentar a forte competição internacional [20].

A excelência em inovação pode ser mais do que apenas um meio de ganhar vantagens competitivas; ela é um fator crítico para a sobrevivência da empresa e determinará sua liderança tecnológica e/ou sua capacidade de permanecer independente [21].

As iniciativas de investimentos em centros de P\&D no Brasil em setores como mecânica e eletroeletrônica são uma realidade e num futuro próximo, além de fortalecer a competitividade, também promoverão a geração de novos postos de trabalho para os engenheiros e pesquisadores [20].

\section{O POLO AUTOMOTIVO DA REGIÃO SUL FLUMINENSE}

O polo automotivo da região sul fluminense teve a sua origem nos anos 1990, motivado pela abertura do mercado para produtos estrangeiros, pelo modelo de atração de investimentos externos implantado com o "novo regime automotivo" e pelos incentivos fiscais criados nos três níveis de Governos - federal, estadual e municipal [22].

Nesta época, o Estado do Rio de Janeiro conseguiu atrair os investimentos de montadoras como a Volkswagen Caminhões e Ônibus [hoje MAN Latin America] que se instalou em 1996 e da PSA Peugeot-Citroën que inaugurou a sua linha de montagem em 2001 [22].

Atualmente, o polo automotivo do sul fluminense é composto de fabricantes de veículos de passeio, caminhões, ônibus, máquinas para a construção civil e diversos fornecedores de autopeças [12]. Um breve histórico das principais empresas presentes na região sul fluminense é apresentada na Figura 4. 
Figura 4: Principais Empresas do Polo Automotivo do Sul Fluminense.

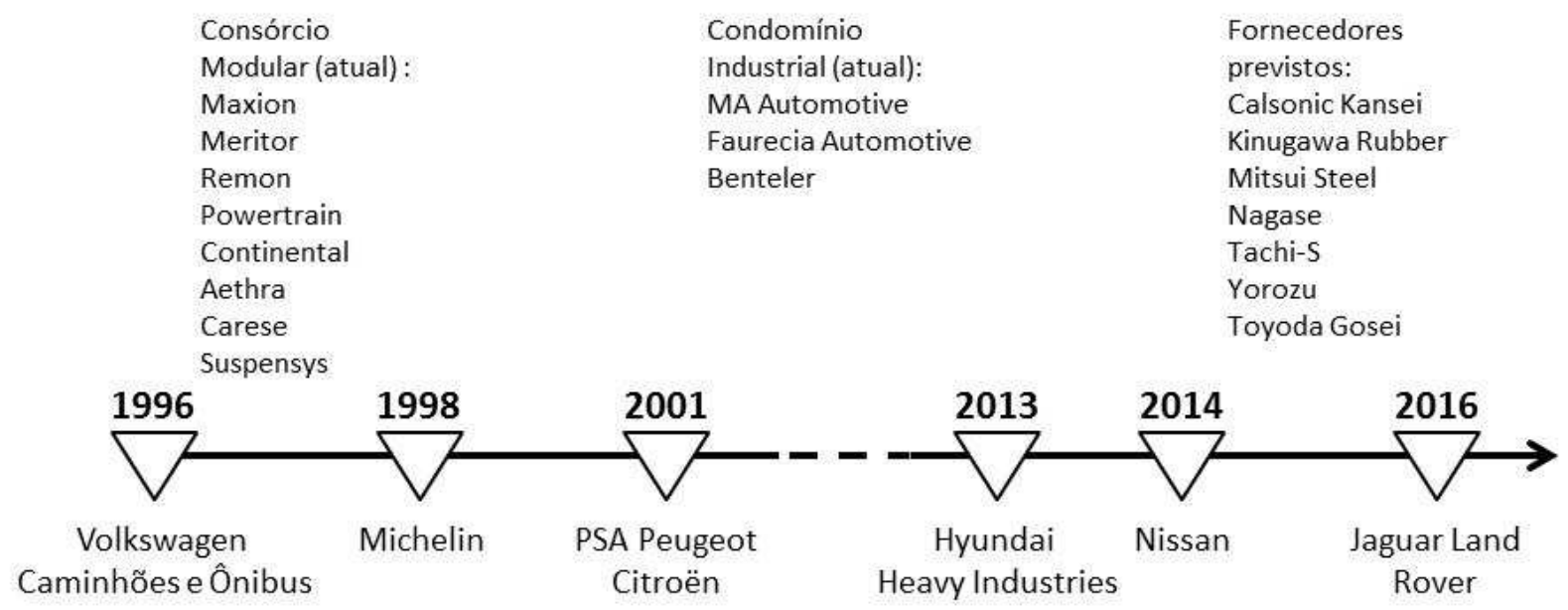

Fonte: Autores.

O crescimento do polo automotivo do sul do Estado do Rio de Janeiro é uma realidade em volume de recursos e em geração de postos de trabalho. Entre 2000 e 2011, mais de sete mil empregos foram gerados na indústria automobilística local [23]. E, em 2013, o Estado do Rio de Janeiro respondeu por 5,5\% da produção de veículos no Brasil [1].

De acordo com o Secretário de Desenvolvimento Econômico, Energia, Indústria e Serviços do Estado do Rio de Janeiro, "o RJ caminha para se tornar o $2^{\circ}$ maior polo automobilístico do país e isso é uma revolução na indústria local, não só pelas grandes empresas que já se instalaram no Estado, mas principalmente pelos fornecedores que estão chegando e devem se multiplicar nos próximos anos" [24].

\subsection{O Cluster Automotivo do Sul Fluminense}

O Cluster Automotivo é um exemplo da construção de alianças estratégicas no sul fluminense [14]. Criado em abril de 2013, a partir da iniciativa da MAN Latin America, Michelin, Nissan e PSA Peugeot Citroën, o Cluster Automotivo tem como objetivos estimular a competitividade e promover o crescimento sustentável da indústria automotiva na região [25], [26].

Os cinco eixos fundamentais nos quais o Cluster Automotivo está trabalhando para alavancar os negócios automotivos no sul fluminense são: habitação, energia, transporte, telecomunicações e mão de obra [25], [26]. Para isso deverão ser desenvolvidas ações de curto e médio prazos envolvendo os governos municipais e estadual, agências reguladoras e concessionárias [26].

Atualmente também integram o Cluster Automotivo outras treze empresas: AKC Aethra, Benteler, BMB, Carese, Continental, CSN Galvasud, Faurecia, MA Automotive, Maxion, Meritor, Powertrain, Remon e Suspensys [26]. 
As perspectivas futuras também são bastante relevantes e indicam que o Cluster Automotivo deverá receber investimentos de mais de $\mathrm{R} \$ 5$ bilhões até 2015 e é esperada uma geração de 45 mil empregos na região até 2020 [25], [26].

\section{MÉTODOS DA PESQUISA}

As empresas escolhidas para participar da pesquisa produzem ou montam os seguintes produtos na região sul fluminense: peças estampadas, bancos automotivos, painéis de instrumentos, eixos dianteiros, eixos traseiros, sistema de freios, rodas, cubos e pneus.

O critério de seleção utilizado na escolha dos fornecedores de autopeças foi o de possuir uma planta produtiva na região sul fluminense. Isto se justifica, pois aumentaria a possibilidade de se ter uma estrutura de engenharia local nestes fornecedores. Vale lembrar que existem fornecedores de autopeças que também estão presentes na região, porém possuem apenas operações logísticas para atender o fluxo síncrono das montadoras.

A população participante da pesquisa foi composta de diretores de plantas e sua equipe direta como: gerentes de engenharia, gerentes de produção, gerentes comerciais e gerentes de qualidade.

A pesquisa de campo foi realizada por meio de um questionário contendo questões fechadas e abertas. A estrutura do questionário foi elaborada em quatro blocos de questões da seguinte forma: a primeira parte era composta de questões cujo objetivo era conhecer nas empresas qual a importância dos temas de P\&D e engenharia; na segunda parte as questões foram direcionadas para identificar a existência de projetos de $P \& D$ e inovação em curso nas empresas; a terceira parte as questões tinham o propósito de saber quais os projetos de P\&D e engenharia em curso nestas empresas tinham coparticipação das montadoras, e a quarta parte foi utilizada para buscar a posição das empresas referentes à comunicação e discussão interna sobre o Inovar-Auto.

As três primeiras partes do questionário compreenderam somente questões fechadas às quais foram integralmente baseadas nos requisitos específicos do Inovar-Auto. Utilizou-se uma escala Likert com seis níveis como forma de mensurar o grau de concordância ou discordância dos entrevistados [Apêndice].

$\mathrm{Na}$ avaliação das respostas, para identificar quais eram as atividades de $\mathrm{P} \& \mathrm{D}$ e engenharia mais e menos desenvolvidas nos fornecedores de autopeças, foi utilizado o critério do somatório dos percentuais nos dois extremos da escala. Ou seja, foram somados os percentuais de bem desenvolvida e plenamente desenvolvida e também os critérios de minimamente desenvolvida ou inexistente, conforme é apresentado no próximo capítulo.

\section{RESULTADOS E DISCUSSÕES}

Do total de sete fornecedores de autopeças escolhidos, os quais foram enviados os questionários, obteve-se o retorno de $85 \%$ deles. Este percentual é considerado excepcional para pesquisas desse tipo [27]. 
$\mathrm{Na}$ primeira parte do questionário foi solicitado aos executivos que avaliassem o grau de desenvolvimento de atividades de $\mathrm{P} \& \mathrm{D}$ e engenharia em suas respectivas empresas. A Figura 5 apresenta os dados consolidados.

Figura 5: Grau de Desenvolvimento de Atividades de P\&D e Engenharia nos Fornecedores de Autopeças do Sul Fluminense.

\begin{tabular}{|c|c|c|c|c|c|c|c|}
\hline & $\begin{array}{l}\text { Atividades de P\&D e Engenharia } \\
\text { nforme requisitos do Inovar-Auto }\end{array}$ & 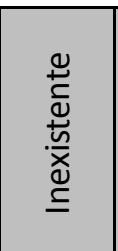 & 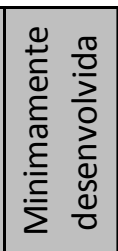 & 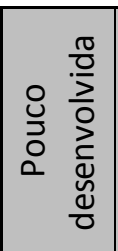 & 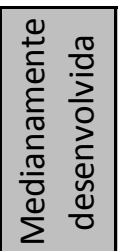 & 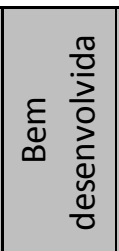 & 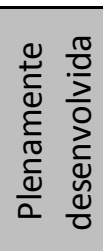 \\
\hline 1 & Pesquisa Básica Dirigida & $7,7 \%$ & $0,0 \%$ & $23,1 \%$ & $23,1 \%$ & $30,8 \%$ & $15,4 \%$ \\
\hline 2 & Pesquisa Aplicada & $7,7 \%$ & $0,0 \%$ & $0,0 \%$ & $23,1 \%$ & $53,8 \%$ & $15,4 \%$ \\
\hline 3 & Desenvolvimento Experim & $7,7 \%$ & $0,0 \%$ & $7,7 \%$ & $15,4 \%$ & $46,2 \%$ & $23,1 \%$ \\
\hline 4 & Serviço de Apoio Técnico & $0,0 \%$ & $23,1 \%$ & $7,7 \%$ & $15,4 \%$ & $30,8 \%$ & $23,1 \%$ \\
\hline 5 & $\begin{array}{l}\text { Desenvolvimento de novos } \\
\text { dispositivos de segurança veicular } \\
\text { ativa e passiva }\end{array}$ & $23,1 \%$ & $7,7 \%$ & $0,0 \%$ & $7,7 \%$ & $38,5 \%$ & $23,1 \%$ \\
\hline 6 & Desenvolvimento de Engenharia & $0,0 \%$ & $0,0 \%$ & $0,0 \%$ & $23,1 \%$ & $46,2 \%$ & $30,8 \%$ \\
\hline 7 & Tecnologia Industrial Básica & $0,0 \%$ & $0,0 \%$ & $0,0 \%$ & $23,1 \%$ & $46,2 \%$ & $30,8 \%$ \\
\hline 8 & Desenvolvimento de Produtos & $0,0 \%$ & $0,0 \%$ & $0,0 \%$ & $23,1 \%$ & $30,8 \%$ & $46,2 \%$ \\
\hline 9 & \begin{tabular}{|l} 
Construção de Laboratórios de \\
Desenvolvimento de Engenharia
\end{tabular} & $15,4 \%$ & $0,0 \%$ & $15,4 \%$ & $23,1 \%$ & $30,8 \%$ & $15,4 \%$ \\
\hline 10 & \begin{tabular}{|l|} 
Construção de Laboratórios de \\
Tecnologia Industrial Básica \\
\end{tabular} & $15,4 \%$ & $7,7 \%$ & $15,4 \%$ & $23,1 \%$ & $30,8 \%$ & $7,7 \%$ \\
\hline 11 & Desenvolvimento de Ferramental & $23,1 \%$ & $0,0 \%$ & $0,0 \%$ & $15,4 \%$ & $23,1 \%$ & $38,5 \%$ \\
\hline 12 & Treinamento de Pessoal & $0,0 \%$ & $7,7 \%$ & $15,4 \%$ & $15,4 \%$ & $46,2 \%$ & $15,4 \%$ \\
\hline 13 & Capacitação de Fornecedores & $7,7 \%$ & $30,8 \%$ & $7,7 \%$ & $30,8 \%$ & $23,1 \%$ & $0,0 \%$ \\
\hline
\end{tabular}

Fonte: Autores.

A partir da lista de atividades de $P \& D$ e engenharia mencionadas na primeira parte da pesquisa foi solicitado aos executivos que indicassem quais possuíam projetos em curso em suas empresas. O resultado em termos percentuais é apresentado na Figura 6. 
Figura 6: Repartição de Projetos de P\&D e Engenharia em curso nos Fornecedores de Autopeças do Sul Fluminense.

\begin{tabular}{|c|l|c|}
\hline \multicolumn{2}{|l|}{$\begin{array}{c}\text { Atividades de P\&D e Engenharia conforme } \\
\text { requisitos do Inovar-Auto }\end{array}$} & $\begin{array}{c}\text { \% dos fornecedores } \\
\text { pesquisados que afirmam } \\
\text { ter projetos em curso } \\
\text { relacionados a estas } \\
\text { respectivas atividades }\end{array}$ \\
\hline 1 & Pesquisa Básica Dirigida & $30,8 \%$ \\
\hline 2 & Pesquisa Aplicada & $38,5 \%$ \\
\hline 3 & Desenvolvimento Experimental & $61,5 \%$ \\
\hline 4 & Serviço de Apoio Técnico & $46,2 \%$ \\
\hline 5 & $\begin{array}{l}\text { Desenvolvimento de novos dispositivos } \\
\text { de segurança veicular ativa e passiva }\end{array}$ & $23,1 \%$ \\
\hline 6 & Desenvolvimento de Engenharia & $84,6 \%$ \\
\hline 7 & Tecnologia Industrial Básica & $30,8 \%$ \\
\hline 8 & Desenvolvimento de Produtos & $76,9 \%$ \\
\hline 9 & $\begin{array}{l}\text { Construção de Laboratórios de } \\
\text { Desenvolvimento de Engenharia }\end{array}$ & $38,5 \%$ \\
\hline 10 & $\begin{array}{l}\text { Construção de Laboratórios de } \\
\text { Tecnologia Industrial Básica }\end{array}$ & $15,4 \%$ \\
\hline 11 & Desenvolvimento de Ferramental & $30,8 \%$ \\
\hline 12 & Treinamento de Pessoal & $61,5 \%$ \\
\hline 13 & Capacitação de Fornecedores & $23,1 \%$ \\
\hline
\end{tabular}

Fonte: Autores.

$\mathrm{Na}$ terceira parte da pesquisa, foi pedido que os fornecedores indicassem dentre os projetos em curso de P\&D e engenharia, quais deles estavam sendo realizados em parceira com alguma montadora. A Figura 7 apresenta estes resultados. 
Figura 7: Repartição dos Projetos de P\&D e Engenharia em curso nos Fornecedores de Autopeças do Sul Fluminense executados em Parceria com Montadoras.

\begin{tabular}{|c|l|c|}
\hline \multicolumn{2}{|c|}{$\begin{array}{c}\text { Atividades de P\&D e Engenharia conforme } \\
\text { requisitos do Inovar-Auto }\end{array}$} & $\begin{array}{c}\text { \% dos fornecedores } \\
\text { pesquisados que afirmam } \\
\text { ter projetos em curso e em } \\
\text { parceria com montadoras } \\
\text { relacionados a estas } \\
\text { respectivas atividades }\end{array}$ \\
\hline 1 & Pesquisa Básica Dirigida & $0,0 \%$ \\
\hline 2 & Pesquisa Aplicada & $0,0 \%$ \\
\hline 3 & Desenvolvimento Experimental & $15,4 \%$ \\
\hline 4 & Serviço de Apoio Técnico & $0,0 \%$ \\
\hline 5 & $\begin{array}{l}\text { Desenvolvimento de novos dispositivos } \\
\text { de segurança veicular ativa e passiva }\end{array}$ & $0,0 \%$ \\
\hline 6 & Desenvolvimento de Engenharia & $46,2 \%$ \\
\hline 7 & Tecnologia Industrial Básica & $0,0 \%$ \\
\hline 8 & Desenvolvimento de Produtos & $69,2 \%$ \\
\hline 9 & $\begin{array}{l}\text { Construção de Laboratórios de } \\
\text { Desenvolvimento de Engenharia }\end{array}$ & $0,0 \%$ \\
\hline 10 & $\begin{array}{l}\text { Construção de Laboratórios de } \\
\text { Tecnologia Industrial Básica }\end{array}$ & $0,0 \%$ \\
\hline 11 & Desenvolvimento de Ferramental & $15,4 \%$ \\
\hline 12 & Treinamento de Pessoal & $15,4 \%$ \\
\hline 13 & Capacitação de Fornecedores & $38,5 \%$ \\
\hline
\end{tabular}

Fonte: Autores.

E na última parte da pesquisa, foi solicitado aos executivos que dessem a sua opinião sobre duas questões referentes à comunicação e discussão interna sobre o Inovar-Auto. Os resultados estão descritos na Figura 8.

Figura 8: Posição dos Fornecedores de Autopeças do Sul Fluminense a respeito da Comunicação e Discussão sobre o Inovar-Auto.

\begin{tabular}{|l|c|c|}
\hline \multicolumn{1}{|c|}{ Questões } & Não & Sim \\
\hline $\begin{array}{l}\text { Em sua opinião as regras do Novo Regime } \\
\text { Automotivo Brasileiro foram devidamente } \\
\text { comunicadas e são claras para a sua } \\
\text { empresa? }\end{array}$ & $83,3 \%$ & $16,7 \%$ \\
\hline $\begin{array}{l}\text { Na sua empresa, já houve internamente } \\
\text { alguma discussão sobre o Novo Regime } \\
\text { Automotivo Brasileiro e suas possíveis } \\
\text { implicações no plano de negócios da } \\
\text { organização? }\end{array}$ & $50,0 \%$ & $50,0 \%$ \\
\hline
\end{tabular}

Fonte: Autores. 
A partir das informações da Figura 5, procurou-se identificar quais eram as atividades de P\&D e engenharia mais e menos desenvolvidas nos fornecedores de autopeças. Percebe-se que são oito as atividades apontadas pelos fornecedores como sendo as mais ou plenamente desenvolvidas em suas empresas, são elas: $2,3,5,6,7,8,11$ e 12 . E são apenas duas as atividades menos desenvolvidas ou inexistentes: 5 e 13 .

Em relação aos dados da Figura 6, verifica-se que todas as atividades de P\&D e engenharia previstas no Inovar-Auto são desenvolvidas em todos os fornecedores pesquisados. Entretanto, as que obtiveram um maior percentual são: 3, 6, 8 e 12.

Já os dados da Figura 7 mostram uma informação relevante. Embora todos os fornecedores realizem as treze atividades de $\mathrm{P} \& \mathrm{D}$ e engenharia em suas respectivas empresas, apenas seis delas $(3,6,8,11,12$ e 13$)$ estão sendo realizadas em parceira com alguma montadora.

$\mathrm{Na}$ última parte do questionário, verifica-se que para a grande maioria dos fornecedores de autopeças, aproximadamente $83 \%$, concordam que as regras do Inovar-Auto não foram comunicadas adequadamente. Já em relação à realização de discussões internas sobre o programa, somente em metade das empresas houve alguma iniciativa neste sentido.

\section{CONCLUSÃO}

Com o Inovar-Auto é inaugurado uma nova fase para a indústria automotiva nacional na qual o incentivo à $P \& D$ e engenharia são os principais vetores para o desenvolvimento de uma infraestrutura tecnológica sustentável para o setor.

Se por um lado o Inovar-Auto beneficia somente às montadoras através do crédito de IPI, do outro lado, ele busca favorecer toda a cadeia automotiva, estimulando a formação de cooperações das montadoras com seus fornecedores, parceiros e instituições de ciência e tecnologia para o cumprimento dos requisitos de investimentos em P\&D e em engenharia, tecnologia industrial básica e capacitação de fornecedores.

A pesquisa de campo evidencia um resultado contrastante ao estímulo destas cooperações. Embora os principais fornecedores de autopeças do sul fluminense afirmam ter projetos em curso em todas as treze atividades de $\mathrm{P} \& \mathrm{D}$ e engenharia previstas no Inovar-Auto; verifica-se que somente em seis destas atividades, os respectivos projetos estão sendo executados em parceira fornecedor-montadora. Este percentual ainda modesto sugeri que progressos sejam feitos de modo a estimular uma maior cooperação entre fornecedores e montadoras no sul fluminense.

Outro ponto bastante relevante revelado na pesquisa é a necessidade de melhorar a comunicação e a explicação das regras do Inovar-Auto entre os atores do setor automotivo no sul fluminense. Talvez, esta falta de um maior conhecimento do programa, de alguma forma, justifique o reduzido percentual de parcerias entre fornecedores e montadoras do sul fluminense em projetos relativos às atividades de $\mathrm{P} \& \mathrm{D}$ e engenharia. 
Apesar destas dificuldades apontadas pela pesquisa, é fundamental fazer um maior desdobramento do Inovar-Auto na região sul fluminense. Por exemplo, através da organização de fóruns, palestras e apresentações, de modo a promover um amplo debate sobre o tema. Neste aspecto, o Cluster Automotivo poderá exercer um papel chave para o incentivo destas iniciativas entre os seus membros.

Desta forma, espera-se que o conhecimento mais abrangente do Inovar-Auto e de uma maior cooperação entre fornecedores e montadoras em projetos de $\mathrm{P} \& \mathrm{D}$ e engenharia possam contribuir para o um maior desenvolvimento tecnológico da indústria automotiva no sul fluminense.

\section{REFERÊNCIAS}

[1] ANFAVEA - Associação Nacional dos Fabricantes de Veículos Automotores. Anuário da Indústria Automobilística Brasileira, São Paulo (2014). Disponível em: http:// www.anfavea.com.br. Acesso em: 20/01/2014.

[2] OICA - International Organization of Motor Vehicle Manufacturers. World motor vehicle production by country and type (2013a). Disponível em: http://www.oica.net. Acesso em: 19/01/2014.

[3] OICA - International Organization of Motor Vehicle Manufacturers. World motor vehicle sales by country and type (2013b). Disponível em: http://www.oica.net. Acesso em: 19/01/2014.

[4] CNI - Confederação Nacional da Indústria. A Indústria Automobilística e Sustentabilidade (2012). Disponível em: http://www.cni.org.br/portal/data/pages/FF80808137E2BEF70138013980B84DD1.htm. Acesso em: 22/01/2014.

[5] ROLAND BERGER. Regime automotivo fará o Brasil alcançar a Coreia do Sul em produção (2012). Disponível em: http://www.rolandberger.com.br/news/2012-11-21regime_automotivo_fara_brasil_alcancar_coreia.html. Acesso em: 22/01/2014.

[6] KPMG. Global Automotive Retail Market. From selling cars on the spot to centrally managing the retail grid (2013). Disponível em: http://www.kpmg.com/Global/en/IssuesAndInsights/ArticlesPublications/Documents/globalautomotive-retail-market-study-part1.pdf. Acesso em: 22/01/2014.

[7] MDIC - Ministério do Desenvolvimento, Indústria e Comércio, Lei No 12.715. (2012a). Disponível em: http://www.planalto.gov.br/ccivil_03/_ato2011-2014/2012/lei/112715.htm. Acesso em: 26/01/2014.

[8] MDIC - Ministério do Desenvolvimento, Indústria e Comércio, Decreto $\mathbf{N}^{\mathbf{0}} \mathbf{7 . 8 1 9}$. (2012b). Disponível em: http://www.planalto.gov.br/ccivil_03/_ato20112014/2012/Decreto/D7819.htm. Acesso em: 26/01/2014. 
[9] IBUSUKI, U., BERNARDES, R. C., CONSONI, F., SAITO, O. M. (2012). New Brazilian Automobile Industrial Policy (Plano Brasil Maior): risks and opportunities for the sector. 20th International Colloquium of GERPISA, 30th-31st of May and 1st of June 2012, Krakow, Poland.

[10] IBUSUKI, U., KOBAYASHI, H., JIN, Y. (2013). Asian Automobile Manufacturers Strategies in Brazil: Impact of the New Automotive Policy (INOVAR-AUTO). 21st International Colloquium of GERPISA, 12th-14th of June 2013, Paris, France.

[11] LEÃO C., GOULART, L. (2013). O INOVAR AUTO e os investimentos em P\&D no setor automotivo. Disponível em: http://pt.slideshare.net/Inovacao/inovar-auto. Acesso em: 25/01/2014.

[12] ANFAVEA - Associação Nacional dos Fabricantes de Veículos Automotores. Anuário da Indústria Automobilística Brasileira, São Paulo (2012). Disponível em http:// www.anfavea.com.br. Acesso em 20/01/2014.

[13] CASSIANO, C., MOREIRA, R., IBUSUKI, U. (2013). Modelo de Gestão de colaboração com Fornecedores Estudo de caso aplicado na Montadora. XXI Simpósio Internacional de Engenharia Automotiva, 22 e 23 de Agosto de 2013, São Paulo, SP, Brasil.

[14] FERREIRA FILHO, V. S., PASCOAL, E. T., SILVA, A. C., OLIVARES, G. L., ROCHA, H. M. Inovar-Auto \& Alianças Estratégicas: Um novo cenário de cooperação para Montadoras e Fornecedores de Auto-peças. X SEGet - Simpósio de Excelência em Gestão e Tecnologia, 23 a 25 de Outubro de 2014, Resende, RJ, Brasil.

[15] MARX, R., MELLO, A. M. (2013). New Initiatives, Trends and Dilemmas for the Brazilian Automotive Industry: The case of Inovar Auto and its impacts on Electro Mobility in Brazil. 21st International Colloquium of GERPISA, 12th-14th of June 2013, Paris, France.

[16] ICCT - International Council on Clean Transportation, Brazil's INOVAR-AUTO incentive program (2013). Disponível em: http:// www.theicct.org. Acesso em: 24/01/2014.

[17] GORGULHO, G. Estudo revela papel de destaque do setor de autopeças na cadeia de inovação (2012). Inovação Unicamp. Disponível em: http://www.inovacao.unicamp.br/destaques/estudo-revela-papel-de-destaque-do-setor-deautopecas-na-cadeia-de-inovacao. Acesso em: 07/05/2014.

[18] PINTEC - Pesquisa de Inovação (2011). Disponível em: http://www.pintec.ibge.gov.br/downloads/pintec2011\%20publicacao\%20completa.pdf. Acesso em: 07/05/2014.

[19] FRANCO, C. Como Decifrar a Inovação para a Indústria Evoluir. Revista Automotive Business, São Paulo, SP, p.36-41, Ano 6, v.26, Abril 2014. 
[20] MCTI - Ministério da Ciência, Tecnologia e Inovação. Relatório Anual da Utilização dos Incentivos Fiscais Ano Base 2012 (2013). Disponível em:

http://www.mct.gov.br/upd_blob/0229/229781.pdf. Acesso em: 07/05/2014.

[21] KPMG. KPMG's Global Automotive Executive Survey 2014. Strategies for a fastevolving market (2014). Disponível em:

http://www.kpmg.com/global/en/issuesandinsights/articlespublications/global-automotiveexecutive-survey/pages/default.aspx. Acesso em: 22/01/2014.

[22] RAMALHO, J. R., SANTANA, M. A., 2002, “A Indústria automobilística no Rio de Janeiro: relações de trabalho em um contexto de desenvolvimento regional". In:

NABUCO, M. R., NEVES, M. A., CARVALHO NETO, A. M. (Orgs.), Indústria

Automotiva: a nova geografia do setor produtivo, cap. 03, Rio de Janeiro, DP\&A Editora.

[23] FREITAS, G. Setor automotivo no Sul Fluminense ganha grupo de discussão (2013). Disponível em: http://www.rj.gov.br/web/imprensa/exibeconteudo?article-id=1539285.

Acesso em: 09/05/2014.

[24] RAMOS, J. Setor automotivo acelera desenvolvimento do Sul Fluminense (2012).

Disponível em: http://www.rj.gov.br/web/imprensa/exibeconteudo?article-id=928559. Acesso em: 10/05/2014.

[25] ECONOMIA RIO. Indústria, pessoas, infraestrutura: O Cluster do Sul Fluminense (2014). Rio de Janeiro, RJ, p.34-37, Ano 01, Edição 01, Março 2014.

[26] FIRJAN - Federação das Indústrias do Estado do Rio de Janeiro. Indústria automotiva prevê 45 mil novos empregos na Região Sul Fluminense até 2020 (2013). Disponível em: http://www.firjan.org.br/data/pages/2C908CEC427BC58F01429603BAD124F3.htm. Acesso em: 10/05/2014.

[27] MALHOTRA, M. K. \& GROVER, V. 1998. An assessment of survey research in POM: from constructs to theory. Journal of Operations Management, v.16, i.4, 1998, pp.407-425. 


\section{APÊNDICE}

Dados do respondente:

\section{Questionário de Pesquisa de Campo}

\begin{tabular}{|l|l|}
\hline Empresa: & \\
\hline Nome: & \\
\hline Cargo: & \\
\hline
\end{tabular}

OBS: A empresa participante da pesquisa não terá seus dados identificados. Ao final do trabalho, lhe será apresentado um relatório executivo com as conclusões do estudo. Nossa intenção é trazer contribuições no campo do Novo Regime Automotivo Brasileiro para o fortalecimento dos negócios na região sul fluminense.

Escala:

\begin{tabular}{|c|c|c|c|c|c|}
\hline \hline 1 & 2 & 3 & 4 & 5 & 6 \\
\hline Inexistente & $\begin{array}{c}\text { Minimamente } \\
\text { desenvolvida }\end{array}$ & $\begin{array}{c}\text { Pouco } \\
\text { desenvolvida }\end{array}$ & $\begin{array}{c}\text { Medianamente } \\
\text { desenvolvida }\end{array}$ & $\begin{array}{c}\text { Bem } \\
\text { desenvolvida }\end{array}$ & $\begin{array}{c}\text { Plenamente } \\
\text { desenvolvida }\end{array}$ \\
\hline
\end{tabular}

$1^{a}$ parte: Assinale, segundo a escala acima, a opção que representa sua opinião quanto ao grau de atividades realizadas na sua empresa relacionadas aos itens abaixo.

\begin{tabular}{|c|c|c|c|c|c|c|}
\hline & 1 & 2 & 3 & 4 & 5 & 6 \\
\hline 1) Pesquisa Básica Dirigida & & & & & & \\
\hline 2) Pesquisa Aplicada & & & & & & \\
\hline 3) Desenvolvimento Experimental & & & & & & \\
\hline 4) Serviço de Apoio Técnico & & & & & & \\
\hline 5) Desenvolvimento de novos dispositivos de segurança veicular ativa e passiva & & & & & & \\
\hline 6) Desenvolvimento de Engenharia & & & & & & \\
\hline 7) Tecnologia Industrial Básica & & & & & & \\
\hline 8) Desenvolvimento de Produtos & & & & & & \\
\hline 9) Construção de Laboratórios de Desenvolvimento de Engenharia & & & & & & \\
\hline 10) Construção de Laboratórios de Tecnologia Industrial Básica & & & & & & \\
\hline 11) Desenvolvimento de Ferramental & & & & & & \\
\hline 12) Treinamento de Pessoal & & & & & & \\
\hline 13) Capacitação de Fornecedores & & & & & & \\
\hline
\end{tabular}

$2^{\text {a }}$ parte: A sua empresa tem ações, projetos ou investimentos atualmente em curso em sua planta relacionados a algum dos itens anteriores?

\begin{tabular}{|c|c|c|c|c|c|c|c|c|c|c|c|c|c|c|}
\hline Não & & 1 & 2 & 3 & 4 & 5 & 6 & 7 & 8 & 9 & 10 & 11 & 12 & 13 \\
\hline Sim & Quais? & & & & & & & & & & & & & \\
\hline
\end{tabular}

$3^{\mathrm{a}}$ parte: Em caso afirmativo na pergunta anterior; estas ações estão sendo realizadas em parceria com alguma montadora?

\begin{tabular}{|l|l|l|l|l|l|l|l|l|l|l|l|l|l|l|}
\cline { 3 - 14 } Não & & 1 & 2 & 3 & 4 & 5 & 6 & 7 & 8 & 9 & 10 & 11 & 12 & 13 \\
\hline Sim & Quais? & & & & & & & & & & & & & \\
\hline
\end{tabular}

$4^{\mathrm{a}}$ parte: Na sua empresa, já houve internamente alguma discussão sobre o Novo Regime Automotivo Brasileiro, denominado de Inovar-Auto e suas possíveis implicações no plano de negócios da organização?

\begin{tabular}{|l|l|}
\hline Não & \\
\hline Sim & \\
\hline
\end{tabular}

Em sua opinião as regras do Novo Regime Automotivo Brasileiro foram devidamente comunicadas e são claras para a sua empresa?

\begin{tabular}{|l|l|}
\hline Não & \\
\hline Sim & \\
\hline
\end{tabular}

